\title{
Astana declaration: a new pathway for primary health care
}

\author{
Katharina Tabea Jungo ${ }^{1} \cdot$ Daniela Anker $^{1} \cdot$ Lea Wildisen $^{1}$
}

Received: 2 May 2019/Revised: 7 March 2020 / Accepted: 2 April 2020/Published online: 21 April 2020

(C) Swiss School of Public Health (SSPH+) 2020

In October 2018, 40 years after the Alma-Ata declaration on primary health care, the Global Conference on Primary Health Care brought together heads of state and heads of government to endorse a new declaration in Astana, Kazakhstan. While the 1978 Alma-Ata declaration focused on building primary healthcare systems, especially in countries with underdeveloped systems, the new declaration adopted a wider scope. It reemphasizes the importance of primary health care to addressing current health challenges, renewing political commitment to primary health care, and achieving universal health coverage (Global Conference on Primary Health Care 2018). In this editorial, we discuss the implications of this new declaration for primary health care.

The first commitment of the Astana declaration is "make bold political choices for health across all sectors." The declaration both continues to promote multi-sectoral action through health in all policies, in line with the WHO framework of the same name, and explicitly discusses including new stakeholders, their accountability, and how to mitigate conflicts of interest, since these are a prevalent concern in the health sector (Institute of Medicine 2009). Bringing new stakeholders to the table is key to addressing current challenges in primary health care as long as adequate measures are taken to reduce conflict of interest and assure accountability. Conflicts of interest occur when a person's or entity's secondary interests may unduly influence its independence or its actions toward its primary interest (World Health Organization 2017). There are policies and toolkits to handle conflicts of interest; for example, the National Health System (NHS) in England

This Editorial is part of the series "Young Researcher Editorials" a training project of the Swiss School of Public Health (SSPH+).

Katharina Tabea Jungo

katharina.jungo@biham.unibe.ch

1 Institute of Primary Health Care (BIHAM), University of Bern, Bern, Switzerland developed a practical toolkit that supports NHS service providers in identifying and managing conflicts of interest (NHS England 2017).

The second commitment is to "build sustainable primary health care." We believe that research and knowledge must be shared to improve the efficiency and innovation of primary health care and ensure its sustainability. In Switzerland and many other countries, primary healthcare research is still a new field of research. The first primary healthcare institute with research activity in Switzerland was created in Basel in 2005. Although the shift toward evidence-based primary health care has already begun in most high-income countries, the process by which knowledge is transferred between research institutions, healthcare professionals, and patients (Yallop et al. 2006) needs improvement. New possibilities for knowledge sharing and increasing data accessibility have been opened by innovative information technologies, and high-income countries should embrace these as they develop their primary healthcare research environments.

The third commitment of the new declaration is to "empower individuals and communities." Community involvement, public participation, and health education are not new to the declaration, but empowerment and health literacy are now included, signaling a shift in our understanding of the public's role in primary health care. In the post-Astana context, people should be given both the knowledge and skills necessary to maintain their health and increase their control over it. Empowering the users of a primary healthcare system also makes the various stakeholders in the system more accountable. The European Patients' Academy on Therapeutic Innovation is an example of an institution founded to empower patients through education (European Patients' Academy 2019). The Astana declaration also involves patients by promoting the use of technological interventions like digital health. In line with this, the NHS England plans to implement on a national scale an evidence-based program based on a smartphone application that targets behavioral change and helps patients adopt a healthier lifestyle including weight loss (Komkova et al. 2019; Liva Healthcare 2019). We 
believe that new technologies, which facilitate patient involvement and make medicine more patient-centered, will improve primary health care.

In the new declaration, we missed a reference to the concept of value-based care, which aims at optimizing health benefits for patients, based on evidence of costs and benefits (Porter 2009). One example of this is the Choosing Wisely campaign, which promotes value-based care by creating evidence-based lists of unnecessary treatments, tests, and services (Cassel and Guest 2012). Since costs often increase without corresponding increases in quality of care, we believe that primary health care should set value-based care as a goal because it makes health care more efficient and sustainable.

We are convinced that the wider scope of the new Astana declaration can serve as a guide for developing primary health care in high-income countries that seek to make primary health care more innovative, inclusive, collaborative, sustainable, and evidence-based.

\section{References}

Cassel CK, Guest JA (2012) Choosing wisely: helping physicians and patients make smart decisions about their care helping physicians and patients make smart decisions. JAMA 307:1801-1802. https://doi.org/10.1001/jama.2012.476

European Patients' Academy (2019) https://www.eupati.eu/. Accessed 13 Mar 2019
Global Conference on Primary Health Care (2018) Declaration on primary health care. Astana

Institute of Medicine (2009) The national academies collection: reports funded by National Institutes of Health. In: Lo B, Field MJ (eds) Conflict of interest in medical research, education, and practice. National Academies Press (US) National Academy of Sciences, Washington. https://doi.org/10.17226/12598

Komkova A, Brandt CJ, Hansen Pedersen D, Emneus M, Sortso C (2019) Electronic health lifestyle coaching among diabetes patients in a real-life municipality setting: observational study. JMIR Diabetes 4:e12140. https://doi.org/10.2196/12140

Liva Healthcare (2019) Living well taking control and liva healthcare team up healthier you: NHS diabetes prevention program. https://livahealthcare.com/liva-lwtc-nhs-fight-against-diabetes/. Accessed 13 Apr 2020

NHS England (2017) Managing conflicts of interest: revised statutory guidance for CCGs 2017. https://www.england.nhs.uk/wp-con tent/uploads/2017/06/revised-ccg-conflict-of-interest-guidancev7.pdf. Accessed 12 Apr 2020

Porter ME (2009) A strategy for health care reform-toward a valuebased system. N Engl J Med 361:109-112. https://doi.org/10. 1056/nejmp0904131

World Health Organization (2017) Safeguarding against possible conflicts of interest in nutrition programmes: draft approach for the prevention and management of conflicts on interest in the policy development and implementation of nutrition programmes at country level-Report by the Director-General

Yallop JJ, McAvoy BR, Croucher JL, Tonkin A, Piterman L (2006) Primary health care research-essential but disadvantaged. Med J Aust 185:118-120

Publisher's Note Springer Nature remains neutral with regard to jurisdictional claims in published maps and institutional affiliations. 